\title{
Integración de monopolios y la oligarquía de los medios en Centroamérica
}

\section{Objetivo}

\author{
- Rick Rockwell \\ American University \\ - Noreene Jonus \\ Consultora independiente \\ Traducción de Albasari Caro
}

Este estudio fue desempeñado en el contexto de una investigación comprensiva sobre las condiciones de los medios de comunicación en Centroamérica. Durante la exploración de las condiciones generales que enfrenta la prensa en esta región, salió a relucir la influencia política que consolida su dominio sobre los medios locales.

Este ensayo explorará la complicada dinámica del dominio de los medios en cinco países centroamericanos (El Salvador, Guatemala, Honduras, Nicaragua y Panamá) y discutirá los cambios en el clima de la vida política de aquellos países. Este estudio también expondrá el efecto del dominio de los medios de comunicación en pocas manos sobre el tráfico libre de información de los periodistas al público, como los límites que impone al desarrollo de medios alternativos en democracias que apenas están floreciendo.

Al estudiar el asunto del dominio de los medios, esta investigación revela que existe un sistema cerrado en el que reducidas élites, con influencia política, controlan el contenido y difusión de las noticias en la región. En la mayoría de 
los países, este sistema no contribuye a la transición hacia un sistema democrático. Este estudio demuestra que tal esquema respalda el traspaso de poder entre las clites de cada ststema. En algunos casos, se cede por completo el poder político a las élites que controlan los medios. Ello resta campo para que se escuche una multitud de voces, lo que indicaría un paso hacia la democracia. En lugar de responder a iniciativas democráticas en la región, los dueños de los medios se han consolidado para eliminar la competencia e incrementar sus ganancias.

Los autores también tienen como objelivo presentar información relativa a la prensa en una región que recibe poca atención en círculos intelectuales y medios de habla inglesa. Fuera de las investigaciones llevadas a cabo por el Programa de Periodismo Internacional en la Universidad Internacional de la Florida, existen pocos estudios a fondo sobre esta dinámica región!

Para hacer cste estudio, los autores viajaron cinco veces a la región, en cl período comprendido entre marzo y agosto de 1998. Cada estadía duró dos scmanas y se concentró en un país del área. El estudio excluye a Costa Rica, porque en ese entonces los autores no viajaron al país para evaluar la situación de los medios. Una gran parte de la información incluida en este estudio proviene de respuestas a una encuesta general sobre los medios (Véase el siguiente aparta(lo), entrevistas y anécdotas de periodistas y propietarios de medios en la región.

\subsection{Metodología}

Las entrevistas personales fueron el método utilizado para recopilar los datos para este estudio. Ello permitió sondear la opinión de los actores en los medios sobre las condiciones actuales. Las preguntas fueron abiertas y semiestructuradas.

Las personas entrevistadas incluyen miembros de los medios en diferentes sectores: escritores, periodistas, editores, gerentes, profesores de periodismo y ducños de medios de comunicación. La lista también toma en cuenta la audiencia de cada medio, a los críticos y miembros de organizaciones profesionales periodísticas.

La muestra de entrevistados fue escogida de la siguiente manera:

Representación: Los entrevistados incluyeron profesionales de todos los periódicos de mayor difusión, cadenas comerciales de televisión, numerosas redes radiales y representantes de destacadas revistas.

Experiencia: El grupo contó con periodistas que tienen varias décadas de experiencia y también con novatos.

Conocimiento: Se entrevistaron a periodistas, analistas de los medios, líderes de opinión política y funcionarios gubernamentales.

Las entrevistas duraron de una a dos horas y fueron complementadas por un análisis diario de los periódicos, programas de televisión y reportajes radiales 
durante el periodo que se condujo el estudio. También se consultaron artículos y literatura sobre el tema.

\section{Integración de monopolios y la oligarquía de los medios}

En una democracia, los medios de comunicación redistribuyen el poder, al tener en sus manos los vehículos para diseminar la información. Surge una situación peligrosa cuando unas pocas personas con aspiraciones políticas se adueñan de los medios. El estado de la prensa en la mayoría de los países centroamericanos demuestra las consecuencias que trae consigo el control de un pequeño grupo elitista, que sacrifica el bienestar de una sociedad en transición a favor de sus intereses políticos y económicos.

El gran desafío a la democracia y la libre expresión de ideas en la región es, quizás, la integración de monopolios de los medios de comunicación y la disminución de voces independientes en el ámbito público.

En Guatemala, menos de una docena de familias controlan todos los medios de comunicación del país. De la misma manera, en Honduras, seis familias ejercen control sobre la mayoría de los medios. En Panamá, con la notable excepción de la asociación propietaria de La Prensa, siete personas o familias controlan cinco de los seis periódicos, dos de las estaciones de televisión de mayor influencia y las estaciones de radio con más alcance en el país. En Guatemala y El Salvador algunos empresarios gozan de un monopolio sobre las cadenas de televisión.

El control de los medios en Honduras ha sido llevado a un gran extremo. El presidente de turno, Carlos Flores Facussé, convirtió su control sobre la prensa en poder político. Flores también es presidente del periódico La Tribuna, controlado por su familia. La familia de Edgardo Dumas Rodriguez, embajador en los Estados Unidos, está entre los inversores minoritarios del periódico.

"Creamos un nuevo estilo de hacer campaña", explicó Rodolfo Dumas CastiIlo, hijo del Embajador Dumas, quien apoya a Flores². "No tuvimos que viajar por todo el país parando en sitios insignificantes. Hicimos nuestra campaña a través de los medios. Utilizamos la prensa porque su poder ha crecido notablemente." Esta nueva estrategia facilitó a Flores un método para sustituir formas tradicionales de campañas políticas, como discursos y asambleas, por el uso de la prensa.

Flores recurrió a todos estos métodos tradicionales durante la campaña de 1997, pero logró conducir su campaña de tal forma que minimizó su uso. Queda claro que su oposición no contó con esta ventaja. Esta desigualdad contradice uno de los principios fundamentales democráticos: el acceso equilibrado a los medios de comunicación para todas las entidades políticas.

Algunas poderosas familias de ascendencia árabe (comúnmente conocidos como turcos) son dueños de una gran parte de los medios en Honduras. Los iurcos llegaron al país al comienzo de siglo y dirigen el Partido Liberal. La 
Prensa, el periódico de mayor alcance en Honduras pertenece a la familia Canahuati. También son dueños de El Heraldo de Tegucigalpa. En marzo de 1998, Jorge Canahuati III he consultor de Vica Televisión, que pertenece a la cadena Canal 3, de San Pedro Sula, controlada por otra próspera familia turca, los Sikaffy ${ }^{3}$. (3) La familia Sikaffy también dirige la estación radial de Tegucigalpa Canal 9, así como La Voz de Centroamérica, una estación que transmite en las bandas de AM y FM en San Pedro Sula.

Según críticos de la prensa, el mayor rival de La Prensa, y el periódico que le sigue en importancia, es El Tiempo de San Pedro Sula, que pertenece a la influyente familia Rosenthal ${ }^{4}$.

Manuel Andonie Fernandez, del grupo que encabeza el Partido Unido (un partido minoritario) controla Radio América, la otra estación radial más escuchada en Honduras. Abraham Andonie es el mayor inversionista en El Nuevo Día, uno de los periódicos más jóvenes del país.

Otro personaje que controla varios medios de comunicación es Rafael Ferrari, un influyente liberal turco, que dirige una agrupación de cuatro cadenas de televisión en Tegucigalpa, el Canal 7 en San Pedro Sula y HRN de Tegucigalpa, una de las estaciones radiales más conocidas en el país.

Algunos periodistas hondureños afirman que el Presidente Flores manipula su apoyo entre los turcos liberales para controlar, no sólo la política del país sino también los medios. Un comentarista reconocido, Rolando Sarmiento, de Radio $X$, alega que fue despedido de su puesto como jefe de redacción de HRN porque el dueño la red de emisoras no estaba convencido de que apoyaba a Flores ${ }^{5}$. Aunque muchos periodistas creen la versión de los hechos presentada por Sarmiento, el jefe de redacción actual de HRN, Raúl Valladares afirma que Sarmiento fue destituido como parte de una campaña de modernización en la cadena y no por razones vinculadas con el Presidente ${ }^{6}$. Juan Ramón Martinez, un destacado columnista de La Tribuna propuso otra teoría. Martinez propuso que, aunque Flores talvez ejercía influencia sobre las decisiones de los dueños y editores de los medios de comunicación, el Presidente no intervenía en las decisiones directamente, para eludir la apariencia de intereses encontrados ${ }^{7}$. Martinez añadió, sin embargo, que un Presidente con tanto poder sobre los medios creaba un ambiente tenso en torno a los periodistas hondureños críticos del gobierno.

Aunque Flores ha enfrentado alguna crítica dentro del sistema hondureño, su poderosa presencia ha obstaculizado el papel de vigilancia ante el gobierno que los medios deben jugar en una democracia. Esto ocurre en un periodo crucial de transición a la democracia en Honduras. Flores controlará el ejército hondureño en cuanto se retire su actual jefe, el General Mario Raúl Hung Pacheco, en 1999. El General Hung fue nombrado a este puesto por el Consejo Supremo de las Fuerzas Armadas (CONSUFFAA), durante la administración del Presidente Carlos Reina, el predecesor de Flores y también miembro del Partido Liberal. 
Durantc su presidencia, Reina no ejcrció el poder constitucional de dirigir el proceso de nombramientos militares. Un Presidente capaz de nombrar el ministro de defensa representa un gran cambio en Honduras. El país ha sido dirigido por dictaduras o juntas militares y por generalcs que controlan al Presidente y a los funcionarios electos, durante casi un siglox. En esta época de transición, Honduras se está alejando de un sistema dirigido por el ejército, que permite poco espacio para voces críticas dentro de los medios. Aunque difícil de detectar, el ascenso de Flores y el papel sumiso que jugaron los medios, forman parte de una transición lógica, teniendo en cuenta la larga historia de control entre los acaudalados.

Indudablemente, los políticos en otros países saben bien cómo utilizar los medios de comunicación para promover sus campañas. Pero ser polílico, dueño de los medios y formar parte de un grupo de élites con intereses similares lleva cl uso de los medios a un nuevo nivel. Tal sistema hermético limita el debate y restringe la variedad dentro del espectro político. Los políticos hondureños dicen esforzarse por establecer la democracia y alejar al ejército del poder. ¿Estarán sustituyendo el antiguo sistema por una moderna junta de los medios?

Los inlluyentes acaudalados - los Canahuati, Sikaffy, Rosenthal, Ferrari y los Facussć (la familia del Presidente Flores) - han logrado concentrar el control de los medios de comunicación de mayor peso político y económico. La mayoría, talvez todas estas familias, tienen grandes inversiones en otras industrias hondureñas. Por ejemplo, antes de iniciar su actual puesto en Vica Televisión, Jorge Canahuati III carecía de experiencia previa en los medios; se ocupaba de las mucblcrías de la familia". Calvin Weddle, uno de los nuevos dueños del diario hondureño, El Periódico, se postuló para candidato presidencial del Partido Liberal; esta táctica corresponde al modelo de provocar el apoyo político entre el pueblo utilizando el poder de los medios ${ }^{\prime \prime \prime}$.

La ascensión al poder de Violeta Barrios de Chamorro en Nicaragua es otro cjemplo del poder al alcance de la cabeza de una familia con una larga historia de intluencia en la vida política del país y también dueña de múltiples medios de comunicación. Aunque Chamorro subió a la presidencia en circunstancias muy diferentes a las de Flores en Honduras. Se argumenta que durante su geslión los medios disfrutaron de más libertades. Algunos periodistas también le acusan de manipular el discurso nacional valiéndose de su poder como Presidenta y poderosa dueña de varios medios. Chamorro alcanzó su popularidad en parte como líder de una amplia coalición antisandinista, y por ser viuda de un editor periodístico asesinado por la dictadura de Somoza en 1970, a principios de la guerra civil en Nicaragua"'.

Después de asumir el poder en 1990, Chamorro finalizó formalmente décadas de censura oficial impuestas sobre los medios por los regímenes de Somoza y del Frente Sandinista. Sin embargo, su administración empleó varios métodos para controlar la información difundida al público. Tanto los directores como el 
equipo del Canal 6 y Radio Nicaragua, en Managua, ambos pertenecientes al gobierno, fueron despedidos repetidamente a raíz del descontento con emisiones noticiosas por parte de la familia Chamorro o la familia Lacayo (Amoldo Alemán Lacayo, antiguo alcalde de Managua y líder del Partido Liberal ocupó la presidencia después de Chamorro) ${ }^{12}$. Aunque los medios sandinistas no fueron afectados, Chamorro controló férreamente la prensa afín al gobierno. Miembros del equipo dicen que oficiales llegaban a diario a las redacciones para controlar los reportajes. El gobierno de Alemán llevó este control a otro nivel al cerrar el Canal 6 y deshacerse de sus redactores, los cuales eran, en su mayoría, antiguos sandinistas.

Chamorro también pretendió controlar los medios no adictos al gobierno. Su administración presionó a los periodistas de varias cadenas en todo el país con amenazas de bloquear la importación de papel. El director de La Tribuna, Joel Gutierrez, reclamó que el gobierno trató de extorsionarlo, advirtiendo que retiraría su publicidad del periódico. El gobiemo proporciona la mayor parte de la publicidad a los medios nicaragüenses. Gutiérrez añade que estas condiciones perduran en la actual administración de Alemán. "Si uno critica al gobierno, aunque esté respaldado con evidencias, el próximo día llama alguien y cortan el programa, ¡aś no más!", explicó Gutierrez ${ }^{13}$. Bajo el gobierno de Alemán, el poder del dinero que representa la publicidad se ha convertido en un arma. En contraste a Chamorro, quien otorgaba publicidad gubernamental a todos los medios, sin importar su inclinación, Alemán sólo aprueba publicidad a medios partidarios del gobierno o afiliados al Partido Liberal. Después de la elección de Alemán, se dejó de lado a un gran número de medios, especialmente los sandinistas (incluyendo la legendaria voz del partido, el periódico Barricada).

En Honduras y Nicaragua, los periodistas que se atreven a ir contra el sistema, produciendo reportajes que perjudican al statu quo, ven sus reportajes alterados o se arriesgan al exilio económico; al ser forzados a tomar puestos en medios de baja categoría o al perder su acceso a trabajar en los medios. En ambos países, los dueños de medios con aspiraciones al poder utilizan su control sobre la prensa. Roberto Montealegre, en Nicaragua, fundó el diario La Tribuna —alineado a los intereses de la gran empresa derechista-, con el propósito de lanzar su carrera política. El empresario Montealegre tenía poca experiencia en el ámbito periodístico. Desde 1996, La Tribuna apoyó al gobierno de Alemán para así obtener fondos de publicidad. En un intento de penetrar el mercado nicaragüense, los dueños de medios en Costa Rica y México han tratado, infructuosamente, de convencer a Montealegre para que venda el periódico ${ }^{14}$.

Un joven reportero de La Tribuna, Eduardo Marenco, explica: "Hay reglas no escritas, pero muy claras: si cruzas cierta línea, te frenan. Si escribes un reportaje sobre ciertos temas, tu editor te llama y te dice: '¿Sabes qué? Esto no lo podemos publicar. Este tipo es el cuñado del dueño del periódico.' El artículo 
nunca es publicado, a pesar de que tienes todos los documentos para comprobar lo que escribiste. Tenemos la libertad de escribir sobre algunos temas pero no sobre otros. Existe una gran red de comunicación entre los sectores políticos y económicos y los medios, en un país pequeño como Nicaragua"15.

En Guatemala, la integración de monopolios en los medios es más manifiesta en el ámbito comercial que en el político. Sin embargo, el gobiemo del Presidente Álvaro Arzú Irigoyen también se sirvió del dinero que representa la publicidad gubernamental para manipular los medios. Dentro del marco de varias medidas en contra de los medios, Arzú retiró la publicidad gubernamental de algunos medios nacionales y boicoté varias publicaciones, entre ellas el semanario Crónica y La Hora, uno de los diarios más establecidos en Guatemala ${ }^{16}$.

Tres familias controlan los medios electrónicos en Guatemala. Durante muchos años una sola familia dominó todas las cadenas radiales. La familia Archila es dueña de trece estaciones (incluyendo una estación de rock que transmite programas en inglés) en todo el país, con una sede ultramoderna y completamente computarizada en el centro de la capital. Su estación de mayor alcance, Emisoras Unidas, mantiene la reputación de ser una emisora sólida, aunque desabrida, que cubre todo el país ${ }^{17}$. La redacción noticiosa goza de acceso a funcionarios y documentos gubernamentales (tal como en muchos países en el área, el gobierno controla los medios al negarles la entrada a fuentes de información) y generalmente presenta puntos de vista tradicionales en la sociedad y política guatemaltecas. La mayoría de los periodistas clasifican a Emisoras Unidas como la estación radial más popular en todo el país.

Sin embargo, la popularidad de Radio Sonora, una emisora exclusivamente noticiosa, basada en la capital, ha crecido últimamente. En las más recientes encuestas, Radio Sonora abarca el 9.2 de la tasa de oyentes (esto significa que el 9.2 por ciento de los habitantes del país escuchó la estación un promedio de una -hora al día), comparado al 6.9 por ciento que sintonizó Emisoras Unidas' ${ }^{1 /}$. Grandes entidades inversoras, que no están asociadas con la familia Archila, están comprando estaciones pequeñas. Radio Sonora es un buen ejemplo de esta nueva tendencia: fue adquirida por Ángel González González, un poderoso acaudalado que controla todas las estaciones de televisión guatemaltecas. González González, un mejicano que vive en Miami, también es dueño de nueve estaciones radiales que transmiten a escala nacional.

El contenido de Radio Grupo Alius, una de las cadenas mayores del país, consiste en programas religiosos. El grupo de treinta estaciones, perteneciente a Alfonso Liu, el líder de una próspera familia sino-guatemalteca de empresarios, transmite programas evangélicos que atraen audiencias católicas y de otras sectas cristianas ${ }^{19}$. Por algún tiempo, el entorno religioso guatemalteco ha sido dominado por varios grupos cristianos que se disputan las conversiones entre la gran mayoría católica del país. El canal estatal de televisión guatemalteco toda- 
vía transmite programas evangélicos, un vestigio de los años 80 , cuando el General Efraín Ríos-Montt, ex Presidente de la República, promulgó conversiones masivas a sqctas evangélicas ${ }^{20}$.

Las redes principales y los potentados de los medios controlan cada vez mayores porciones del mercado guatemalteco, con lo cual dejan poco espacio para contendientes marginales como Crónica y La Hora. En este contexto, operaciones de mediano tamaño son adquiridas, excluidas del mercado o aisladas. En parte, este fenómeno es un resultado secundario de las medidas aplicadas a los medios bajo la administración de Arzú y la presión política en el entomo comercial ejercida sobre las posiciones editoriales de algunas publicaciones y cadenas radiales. Algunos aspectos son también consecuencia de la integración de monopolios.

Un análisis de los medios de comunicación guatemaltecos revela los lazos que existen entre los medios de comunicación y los intereses comerciales. Prensa Libre es el diario de mayor alcance entre siete periódicos de amplia tirada en cl país, todos publicados en la capital ${ }^{21}$. Cinco poderosas familias, incluyendo a los Zarco, los García y los Contreras, fundaron el diario en 1951, y desde ese entonces lo controlan, junto con sus otras publicaciones. El conglomerado también es dueño de El Periódico, fundado por José Rubén Zamora Marroquín cuando partió caminos con Siglo Veintiuno en 1996 a raíz de una disputa. Este grupo también es propietario de Nuestro Diario, una publicación sensacionalista. (Nuestro Diario fue periódico del gobierno durante la dictadura de Jorge Ubico Castañeda en los años treinta. Llegada la siguiente década, el Presidente Juan José Arévalo compró cl periódico y lo dirigió como corporación estatal. Durante los cincuenta, cl diario fue vendido a cinco familias y cambió su nombre a Prensa Libre ${ }^{22}$.) La nueva versión de Nuestro Diario fue establecida como contendiente de Siglo Veintiuno, uno de las publicaciones sensacionalistas más populares del país.

Con estas tres publicaciones, los dueños del Grupo Prensa Libre dominan más de la mitad de los periódicos que circulan en Guatemala ${ }^{23}$. En un esquema moderno dirigen productos muy diferentes a distintos sectores de su audiencia. El Periódico atrae a las élites intelectuales. Nuestro Diario capta a quienes se interesan por chismes del mundo de las estrellas y bajezas sensacionalistas. Prensa Libre es un periódico tradicional que representa los intereses de los empresarios liberales.

Los dueños de Siglo Veintiuno son los mayores competidores de Prensa Libre en el mercado de los medios de comunicación impresos. El grupo de grandes inversores, Corporación de Noticias, fundó su primer periódico en 1990 y desde ese entonces ha expandido sus lucrativas operaciones. Los principales inversores provienen de la familia Castillo, fabricantes de vidrio y distribuidores de cerveza; los Botrán, que también distribuyen licor; los Gutiérrez, familia dueña de 
una cadena de restaurantes; y los Páiz, propietarios de una cadena de supermercados. Al Día, publicación sensacionalista fundada en 1996, es el lanzamiento más reciente de Siglo Veintiuno, y ocupa actualmente el segundo lugar en popularidad entre los periódicos guatemaltecos ${ }^{24}$. Muchos atribuyen (o culpan) al periódico Al Día el triunfo de publicaciones sensacionalistas en Guatemala, que ahora dominan el ámbito de las noticias.

Dos de los periódicos más establecidos del país están en crisis. Fundado en 1963, El Gráfico, controlado por la familia Carpio, distribuye 30,000 ejemplares a diario. Conocedores del negocio se preguntan cómo financian el periódico, puesto que sus páginas contienen poca publicidad. Jorge Carpio Nicolle fundó El Gráfico y lo transformó de una publicación deportiva en la voz de su Partido de Unión Nacional del Centro. Hoy día, el periódico parece no tener línea editorial. La familia Marroquín es propietaria de La Hora. A los setenta años de edad, Óscar Marroquín ha declarado sus intenciones de cerrar el periódico; culpa a un bloqueo, organizado por la administración de Arzú y otras entidades políticas opueslas al periódico, de ocasionar su ruina.

En países como Guatemala y Nicaragua, donde la mayor parte de la publicidad de los medios es de procedencia gubernamental, los dueños estiman que los reportajes críticos al gobierno pueden ocasionar grandes pérdidas de fondos. Este contexto añade el chantaje económico a los métodos tradicionales de control gubernamental sobre los medios, el soborno y los pagos comprometedores. La crítica del gobierno sirve apenas como elemento superficial en un entomo donde los medios mantienen una relación cálida con el gobiemo para proteger sus intereses económicos. Poderosas familias en el mundo de los medios, como los Chamorro en Nicaragua, también se han servido de esta táctica para manipular los medios.

En Guatemala, los medios utilizan su acceso al público para promover otros productos del mismo dueño. Por ejemplo, Siglo Veintiuno a menudo dedica cspacios a los restaurantes, víveres y distribuidores de licor pertenecientes al mismo grupo propietario del periódico. Un fenómeno similar ocurre en Honduras, donde empresarios poderosos utilizan sus negocios para financiar los medios que les pertenecen. Francisco Medina, el nuevo editor de El Periódico, reconoce que sin el apoyo financiero y la publicidad proporcionada por la asociación propictaria de su periódico (encabezado por Calvin Weddle, del Partido Liberal), no tendría suficiente publicidad o recursos para publicar ${ }^{25}$. El editor de El Nuevo Día, Edgardo Benílez, también confiesa que a cada uno de los scis periódicos nacionales le corresponde sólo una pequeña tajada de la publicidad, por lo cual no podrían subsistir sin extenso respaldo económico ${ }^{2 \hbar}$. Editores de los periódicos hondureños de más alcance, pertenecientes a los Rosenthal, los Canahuati y los Facussć declaran que existe suficiente publicidad para financiar sus publicaciones, pero no aclaran si sobrevivirían sin el apoyo aportado por los otros negocios de sus propietarios. 
Este sistema cerrado de control es fácil de observar en el ámbito de la televisión. En Guatemala, por ejemplo, el mercado es dominado por un solo hombre: el previamenté citado Ángel González González, conocido comúnmente en Guatemala como "el mejicano". Este empresario ejerce un monopolio tácito sobre la industria televisiva del país, y pretende integrar sus adquisiciones de cadenas radiales a su imperio. (Por ejemplo, Radio Sonora trasmite el popular programa de televisión Noti7, producido por uno de los canales pertenecientes a González González.) El citado hombre de negocios es accionista mayoritario de los cuatro canales nacionales guatemaltecos. El único canal popular está pasando en estos momentos de manos del ejército a control estatal.

La ley guatemalteca prohibe la adquisición de grandes medios de comunicación por parte de los extranjeros. González González supera esta ley al estar casado con una guatemalteca, a cuyo nombre están todas sus corporaciones en el país. Alberto Fernández, del Servicio de Información de los Estados Unidos (USIS), observa que: "González González mantiene el contenido de sus estaciones poco controvertido. Se acomoda a quien tenga el poder. En estos momentos favorece al PAN (el Partido de Avanzada Nacional guatemalteco) pero intenta conservar buenas relaciones con todos los partidos políticos ${ }^{27}$." González González también sustenta sus privilegios a través de donaciones. Por ejemplo, donó 4 millones de quetzales en publicidad (aproximadamente, $\$ 650,000$ ) al antiguo presidente, Vinicio Cerezo, de los demócratas cristianos para financiar su campaña de $1986^{2 k}$.

Durante varios años González González representó a la gigantesca red mejicana, Televisa, vendiendo programas y publicidad por toda la región. En 1981, tanto Televisa como González González hicieron inversiones en la televisión guatemalteca. Televisa de México todavía posee algunas acciones en dos canales guatemaltecos. Junto con TV Azteca, una nueva red mejicana, González González emprendió inversiones en el Canal 13 de Guatemala ${ }^{24}$. Como resultado la televisión guatemalteca esta repleta de programas mejicanos. En las horas de la mañana dos de las cuatro estaciones del país transmiten noticias de México, las cuales rara vez mencionan a Guatemala. Lo que estas estaciones venden como noticias son meras reproducciones de reportajes de la noche anterior, noticias adapladas de cadenas mejicanas y estadounidenses y programas guatemaltecos de micrófono abierto de baja calidad.

La lealtad de González González al gobierno guatemalteco es tan fuerte que transmite en uno de sus canales el controvertido noticiero Avances, condenado por los medios internacionales por ser un aparato de publicidad del presidente Arzú ${ }^{\text {(1) }}$. El programa fue creado como un noticiero neutro bajo la administración de Ramiro León Carpio, pero ha sido trasformado en una plataforma donde el partido mayoritario, PAN, difunde su causa y ataca a sus enemigos. El objetivo de una gran parte de sus reportajes es negar las aserciones presentadas por otras estaciones de radio y televisión. 
La influencia de González González se extiende más allá de Guatemala. En Nicaragua ya adquirió su tercer canal de televisión. Sus estaciones son preferidas por casi el 20 por ciento de la teleaudiencia nicaragüense, que se divide cntre nueve estaciones. Sin embargo, el 75 por ciento de la audiencia nicaragüense siguc sintonizando el Canal 2, una estación liberal aliada del gobierno, que permanece fuera del dominio de González González". Para comprar estas cstaciones, el empresario mejicano se unió a inversionistas nicaragüenses exiliados desde la era sandinista (dadas sus simpatías con Somoza) que viven en Miami. Irónicamentc, el Canal 4, una de sus nuevas adquisiciones, transmitió programas favorables al sandinismo por varios meses, mientras que González González y sus socios consolidaban y actualizaban sus acciones.

Para evitar que el hombre de negocios mejicano penetrara el mercado panameño, los propietarios de medios de comunicación del país consolidaron algunos sistemas de medios electrónicos. De esta manera, limitan la influencia que González González pueda ejercer si compra los derechos a canales controlados por cl gobicrno estadounidense en la región del Canal.

La familia Eleta y sus adquisiciones en MEDCOM lideran el mercado dc radio y televisión en Panamá. Los canales 4 y 13 pertenecen a MEDCOM; la compañía estima que los dos canales controlan un promedio de 78 por ciento de la tcleaudiencia del país. En el mercado de radioescuchas, los Eleta, los mayores accionistas en MEDCOM, junto con su socio Nicolás González Revilla, pretenden comprar otra estación FM para completar su combo AM-FM y RPC Radio, una colosal estación de noticias e información. Este grupo piensa añadir a su imperio de radio y televisión valiéndose de las ventajas que ofrece el concepto moderno de multiplex (en que una cadena crea canales diferentes para audiencias con gustos específicos) para remplazar el modo tradicional de sacar una sola enorme estación al mercado. RPC domina en parte porque es reconocida como la fuente de información y noticias panameña $a^{12}$.

Muchos panameños se refieren a MEDCOM como "el monopolio", puesto que, al pertenecerle las estaciones de más alcance en Panamá, domina el mercado de radio y televisión y se teme que no le rinden cuentas al público. Algunos panameños, dentro y fuera de los medios, creen que González Revilla manipuló la cobertura de MEDCOM para favorecer al gobierno de su primo Pérez Balladares; especialmente durante su frustrada campaña para cambiar la constilución y así posibilitar su reelección ${ }^{33}$. La percepción de que un gigante como MEDCOM tenga una alianza con el Estado despierta preocupaciones dentro de la oposición en el sentido de que se pueda acallar la voz de los medios. En respuesta al llamado "monopolio", González Revilla aclara que su compañía consolidó fuerzas con los Eletas para que ambos canales de televisión pudieran cvitar que empresarios extranjeros, específicamente el mejicano González González, penetraran el mercado. En cuanto a sus conexiones al gobierno, el 
cjecutivo de MEDCOM respondió: "Si no criticamos ni nos detenemos a pensar en lo negativo, se nos culpa de tener lazos al gobierno. Aquí siempre hay una percepción pojítica. La mayoría de los medios están en contra del gobierno; nos acusan de favorecer al gobierno porque ofrecemos un producto equilibrado".34.

Otros en el mundo de los medios, como Gustavo Gorriti, el editor asociado de La Prensa de Panamá, critican el apetito insaciable de MEDCOM por adquirir las estaciones de radio y televisión del país. "La integración de monopolios en los medios es mucho más peligrosa aquí que en los Estados Unidos," comentó Gorriti. "La calidad del periodismo sufre cuando medios independientes son adquiridos por una misma entidad. ¿Cómo se supone que un periodista ejerza su profesión cuando es controlado por aquellos que representan los sectores políticos más poderosos?" "3s. Los ejecutivos de MEDCOM respondieron a esta crítica cxplicando que simplemente están participando en el mercado global. Tal como las operaciones de González González en Guatemala, MEDCOM ha establecido convenios con Televisa para compartir programación con el enorme centro de producción de televisión y radio mejicano? ${ }^{36}$.

González Revilla afirma que la capacidad de producir dos estaciones separadas con noticieros diferentes protege a MEDCOM no sólo de la competencia mejicana, sino también de noticieros de habla hispana producidos por cadenas en Estados Unidos, como Univisión, y de programas sudamericanos. Gigantescas compañías estadounidenses, como Time Warner (con sus franquicias, HBO y CNN), Disney (con ESPN) y Westinghouse (CBS) navegan todas rumbo a Centroamérica. Ya han establecido una ligera presencia en la región con versiones de sus programas en español. Sin embargo, algunas voces en el país expresan sus sospechas de que MEDCOM está utilizando la competencia internacional como pretexto para apoderarse de todos los medios de comunicación. "Es una cxcusa muy oportuna para justificar sus intentos de dominar el mercado," dijo con desdén Juan Luis Correa, gerente general de La Prensa ${ }^{37}$.

Como en otros países en la región, la más seria amenaza a la libre expresión de ideas en Panamá es el hecho que un puñado de empresarios o de familias posea los más influyentes medios de comunicación. Con la excepción de La Prensa, siete individuos o familias controlan cinco de los seis periódicos del país y también el titán de los medios electrónicos MEDCOM. "Pueda que nos cstemos alejando de la era de caciques de los medios, dijo Gorriti de La Prensa, pero las coincidencias de los medios con intereses comerciales y políticos "lienen una gama de impactos que afectan la esencia de la democracia; ejercen un ef ecto mucho más básico y fundamental sobre el sistema. La adquisición de medios independientes contrarresta los esfuerzos dedicados a mejorar la calidad del periodismo"..".

Panamá sobrepasó la era en que individuos como Gónzalez Gónzalez dominaban el mercado, hoy en día consorcios como el de MEDCOM son más comu- 
nes. Pero en El Salvador la era del cacique sigue vigente. Un hombre domina el mercado de la televisión: Boris Esersky. Es dueño de Telecorporación Salvadoreña (TCS), grupo que incluye una red de tres estaciones que cuentan con gran parte de la teleaudiencia del país ${ }^{34}$. TCS emplea el método de multiplex en su programación. Un canal se dedica casi exclusivamente a las telenovelas, otro a los deportes y el tercero trasmite programas musicales y películas. TCS también controla agencias publicitarias, compañías de relaciones públicas, distribuidores de cable y empresas publicadoras de revistas. En algunas ocasiones, las estaciones de TCS comparten noticieros. A través de TCS, Esersky ejerce una considerable influencia política sobre el sistema salvadoreño, tan poderosa como para lograr que el gobierno cambiara sus planes de venderle una frecuencia de televisión a inversionistas mejicanos ${ }^{41}$.

A pesaí de que San Salvador recibe programas de siete estaciones UHF, el Canal 12 es la única estación del país fuera del control de Esersky y su único competidor en el ámbito de VHF. En 1997, el dueño, Jorge Zedán, le vendió sus derechos a TV Azteca. Ahora el Canal 12 transmite programas mejicanos, que en su gran parte son telenovelas. El Canal 12 disfruta la ventaja de transmitir el noticiero más destacado del país ${ }^{41}$. El grupo de Esersky recibe toda la publicidad, puesto que controla las agencias publicitarias. El Canal 12 recibe la publicidad de negocios que no tienen acceso a TCS a raíz de sus inclinaciones políticas. En 1987, durante la guerra civil salvadoreña, el Canal 12 perdió la parte que le correspondía de publicidad gubernamental al ser calificado como demasiado independiente. Tal como Arzú en Guatemala, el gobierno salvadoreño organizó un boicot contra el canal de Zedán. La estación sobrevivió gracias a su habilidad de ofrecerle un medio a pequeños negocios ${ }^{42}$.

Como agradecimiento por la mano libre que le otorgan para establecer un monopolio virtual sobre la industria televisiva, Esersky of rece espacios gratuitos a políticos, sobre todo, durante sus campañas electorales ${ }^{4 ?}$. A medida que se despiertan sensibilidades a esta práctica, los medios critican la relación comprometedora entre ambos lados. Un editorial de julio, 1998 en El Diario de Hoy comenta:

Hasta ahora nuestros medios han sido aliados del poder oficial, compinches políticos de los intereses económicos y de las ideologías en un estilo periodístico casi feudal. Es hora de que superemos nuestro miedo a ofender a los poderosos que nos proporcionan publicidad. Estos deben darse cuenta que sus intereses son resguardados por medios con una amplia audiencia que consume su producto, y no por los medios que presentan las noticias más manipuladas. Es la ley del mercado"44.

Gorriti, de La Prensa de Panamá, advierte que periodistas no pueden mantener lazos a poderosas organizaciones profesionales, ni pueden actuar independientemente, al recibir órdenes de abstenerse de periodismo objelivo. "Eres sólo 
un clcmento del conglomerado," dice el editor, quien añade que los periodistas son relegados a producir reportajes que carecen de pasión. "Si en realidad se licne la intención de ser periodista hay que separarse de otros intereses 4.

La Prensa de Panamá sc destaca por ser opcrada como una asociación. Miles de inversionistas (incluycndo sus empleados) son propietarios del periódico; y cada uno liene derecho a comprar no más del uno por ciento de las acciones. Está claro que grandes fuerzas políticas y comerciales poseen acciones en cl pcriódico, pero este sistema trata de tomar una ruta un tanto objetiva. Sus detractores en otros medios y ejecutivos, como James Aparicio, director de La Estrella de Panamá, que favorece al gobierno, comenta que el sistema beneficia los intereses de los niveles más altos de su consejo o de su antiguo director, Robcrto Eiscnmann $\mathrm{Jr}^{4 h}{ }^{4}$. Sin cmbargo, la estructura de La Prensa representa por lo menos un csfuerzo de crear equilibrio y objetividad. El liderazgo del diario se ha rchusado a cxlender sus operaciones a otros medios. Hace varios años, a raíz de su influencia cconómica, el consejo de La Prensa tuvo la oportunidad de realilar inversiones en televisión y otros medios electrónicos. Correa, el gerente Łeneral del periódico dice que el conscjo opló por mantenerse al borde de olros ámbitos dado a que su filosofía dicla que una gran variedad de dueños fomenta la democracia ${ }^{47}$.

Esta aclitud se difiere notablemente de la tradición de control por sistemas oligárquicos que causaron la guerra civil en EI Salvador. Las élites salvadoreñas, que acumularon su fortuna con ganancias de la venta de café, son conocidos como Las Catorce Familias ${ }^{4 x}$. Cuando estalló la guerra civil, estas familias, las cuales formaban el dos por ciento de la población, controlaban más del 66 por ciento del terreno en cl país. Con el paso del tiempo, estas divisiones sociales polarizaron la sociedad salvadoreña. Los medios, especialmente la prensa, relle jaban esta fragmentación; periódicos como por ejemplo, El Diario de Hoy (lundado en 1936) y La Prensa Gráfica (fundada en 1915) eran un instrumento de la oligarquía y del partido de extrema derecha ARENA.

En 1998, cuatro editores de alto rango se marcharon de La Prensa Gráfica, y fucron remplazados por un equipo de gerencia nuevo, encabezado por Cecilia Gallardo de Cano, antigua ministra de educación de ARENA. Aunque Gallardo impone respeto dentro del partido, carece de experiencia periodística. En 1996, la familia Dutriz, dueños del diario por largo tiempo, vendieron sus acciones en cl periódico a un grupo de inversionistas conservadores. El nombramiento de Gallardo de Cano para la dirección de La Prensa Gráfica reafirmó la reputación del diario de ser el patrón conservador del país.

El principal contrincante de La Prensa Gráfica, El Diario de Hoy, mantiene una circulación de 100,000 lectores diarios ${ }^{49}$, y es identificado como un periódico ultraconservador, famoso por apoyar a la camarilla de D'Aubuisson dentro del partido ARENA. Este periódico es dirigido por Fabricio Altamirano, un 
empresario conservador educado en los Estados Unidos perteneciente a la tercera generación de la familia que encabeza el diario. En 1998, Altamirano lanzó Más, un diario deportivo y de noticias del mundo de las estrellas para audiencias jóvenes. En los últimos tres años, El Diario de Hoy ha cambiado su apariencia; pasó de ser una publicación corrupta repleta de publicidad de la extrema derecha a transformarse en un diario moderno, independiente y equilibrado.

El Mundo, la publicación de la tarde de mayor alcance en el país, pone en circulación 28,000 ejemplares a diario y es propiedad de la familia Borja, dueña de grandes ejes de agricultura. El periódico dejó de ser una publicación de tendencia moderada y refleja ahora la orientación política de derecha de la familia ${ }^{(5)}$.

Otra publicación de la tarde, Co-Latino, fue fundada en 1890". En 1994, para evitar el cierre del periódico por falta de publicidad, el diario se reorganizó y formó una cooperativa financiada en parte por el FMLN (el Frente Farabundo Martí para la Liberación Nacional, grupo guerrillero durante la guerra civil, convertido ahora en un poderoso bloque de oposición) y en parte por fuentes europeas. Co-Latino representa la única publicación de izquierda en el país, pero padece de una audiencia y red de distribución limitadas.

Esto es una excepción dentro del contexto tradicional salvadoreño, en el que los medios reflejan las opiniones de las élites (con inclinaciones a la derecha) del país $\$ 2$. En general, la mayoría de los dueños no asumen la responsabilidad que implica ser propietario de un medio en una nueva democracia. Enrique Altamiriano, dueño de El Diario de Hoy, supervisor de la gerencia del periódico bajo su propio hijo, dice que ser propietario de un medio de comunicación no se distingue en nada de ser dueño de una franquicia de McDonald's: sus empleados escriben artículos en lugar de freír hamburguesas, y el periodismo en su opinión es sólo una inversión ${ }^{53}$. Altamirano padre opina que los dueños de los medios lienen el derecho de operar su negocio sin medir las consecuencias de sus decisiones para la sociedad y el gobierno.

Cristiana Chamorro, antigua editora de La Prensa de Nicaragua, opina de manera distinta. Desde su punto de vista, en Centroamérica, "la libertad de la prensa beneficia sólo a los propietarios de los medios" y los periodistas, o lienen miedo de descubrir la verdad, o se sienten restringidos por el sistema económico ${ }^{\varsigma 4}$.

\section{Conclusión}

Los obsláculos a la libre expresión de ideas que preocupan a Chamorro y a otros periodistas en la región surge de su percepción de dueños que comprometen su control sobre los medios de comunicación. Opinan que los grandes propietarios con otros intereses comerciales a menudo olvidan el papel de servicio al público que deben desempeñar los medios. A raíz de estos intereses abandonan su misión tradicional de vigilar las actuaciones del gobierno - lo cual, a 
veces, resulta caro y consume mucho tiempo-, y se acoplan a él y mejoran sus ratings, (fomentando así el sensacionalismo y reportajes superficiales) para generar más gạnancias. En este contexto, tal como Altamirano lo describe, los dueños tienen pocas razones para mejorar las habilidades periodísticas de sus empleados, ya que su tarea es la de crear reportajes breves en lugar de trabajos indagatorios. Dado a la integración de monopolios en estos pequeños mercados, y los intereses de los dueños en otros negocios, su control sobre los medios se convierte en una herramienta para hacerle publicidad a sus negocios o para afiliarse a ciertas corrientes políticas con el propósito de incrementar la publicidad que otorga el gobierno en ese ámbito.

Un sistema de censura económica ha sido establecido en toda la región por dueños con otros intereses comerciales que ven los medios como un negocio lucrativo sin tener en cuenta su responsabilidad de servir al público. Fuera de pocas notables excepciones, los medios cuentan con periodistas cuyas críticas de negocios y sectores económicos son reprimidas por que esas empresas lienen lazos sociales, políticos o económicos a los aglomerados propietarios del medio que los emplean. Algunos periodistas en varios países comentan que este sistema provee libertad de expresión sólo para los dueños de los medios y no para sus empleados.

Aquellos dueños que tratan de incrementar sus ganancias, contratan a personas con poca experiencia y les pagan poco; lo cual crea un sistema que fornenta la corrupción y la baja calidad. Dado a que la demanda de empleos en los medios continúa siendo alta en todo el hemisferio, los dueños se aprovechan la abundancia de empleados para mantener los salarios bajos. Entrenar empleados incrementa su valor, lo cual no concuerda con esta ecuación. Sin embargo, La Prensa de Panamá ha comprobado que la calidad editorial puede resultar en éxito cconómico a medida que el público reconoce que disfruta de un producto superior.

La seguridad personal y estabilidad económica de los periodistas en la región sc ve amenazada por un sistema en que aquellos que controlan la publicidad (incluyendo al gobierno) manipulan el contenido de los medios sirviéndose del sistema económico en virtud del cual los dueños pagan bajos salarios. Aunque la seguridad ha mejorado en Guatemala, los periodistas siguen siendo intimidados por las fuerzas económicas y por el gobierno. Recientemente, el desafío de estos términos les ha costado la vida a varios reporteros ${ }^{55}$. Hasta en Panamá, el gobierno ha intentado utilizar su poder para presionar a los autores de artículos que critican su conducta ${ }^{56}$.

Las élites scguirán controlando los medios en esta región, ya que los ciudadanos no gozan de acceso a los medios y los periodistas no desempeñan control sobre la calidad de su trabajo. Estas élites han demostrado que utilizarán este esquema para extraer ganancias, sacrificando un sistema abierto a voces alterna- 
tivas que compitan con la norma. En lugar de fomentar la democracia, este sistema facilita el cambio de poder del ejército a manos de las élites. Ello se da en una zona con escasa tradición de apertura a las fuerzas democráticas y a las voces de los despojados, los desempleados y de quienes no han accedido a la educación. Por ahora y en el futuro próximo, el sistema será utilizado para distraer a estos grupos y así evitar que sus ideas ganen fuerza: una función contraria al papel que el sistema de comunicación debe jugar en un contexto democrático.

\section{Notas}

1. J. Arthur Heise y Charles H. Green, "An Unusual Approach in the United States to Latin American Journalism Education," publicado en: Communication in Latin America: Journalism, Mass Media, and Society, Richard R. Cole (editor). Wilmington, DE: Scholarly Resource, Inc., 1996, página 66.

2. Rodolfo Dumas Castillo, entrevistado por Rick Rockwell el 23 de marzo de 1998 en San Pedro Sula, Honduras.

3. Jorge Canahuati III y un grupo integrado, entre otras personas, por Blanca Sikaffy, presidente de VICA TV y Vilma García, directora de noticias, entrevistadas por Rick Rockwell el 23 de marzo de 1998 en San Pedro Sula, Honduras.

4. John Virtue (editor), Latin American Media Directory. Centro Internacional de Medios, Departamento de Periodismo y Comunicación, Universidad Internacional de la Florida, 1998, página 225.

5. Rolando Sarmiento, Radio X, entrevistado por Rick Rockwell el 16 de marzo de 1998 en Tegucigalpa, Honduras.

6. Raúl Valladares, director de noticias de HRN, entrevistado por Rick Rockwell el 18 de marzo de 1998 en Tegucigalpa, Honduras.

7. Juan Ramón Martínez, de La Tribuna, entrevistado por Rick Rockwell el 18 de marzo de 1998 en Tegucigalpa, Honduras.

8. Thomas E. Skidmore y Peter H. Smith, Modern Latin America. Oxford University Press, Inc., Nueva York, 1992, página 331.

9. Entrevista con Canahuati.

10. Clir. el artículo De Buena Fuente, publicado en La Prensa (Honduras), 22 de marzo de 1998, página 4A.

11. Clir. Skidmore y Smith, páginas 328-330.

12. Harold E. Moore, Jr., Democracy, the Media, and Politics in Nicaragua. Programa de Periodismo en Latinoamérica, Departamento de Periodismo y Comunicación, Universidad Internacional de la Florida, Miami, 1998, página 62.

13. Joel Gutiérrez, director de La Tribuna, entrevistado por Noreen Janus, durante julio de 1998, en Managua, Nicaragua.

14. Ihid.

15. Eduardo Marenco, La Tribuna, entrevistado por Noreen Janus, en julio de 1998 en Managua, Nicaragua.

16. Óscar Marroquín Rojas, director de LaHora, entrevistado por Rick Rockwell, el mes de julio de 1998, en Ciudad de Guatemala, Guatemala.

17. Ileana Alamilla, Joaquín Pérez, Ruth Taylor (editores), The Guatemalan Media: The Clicallenge of Democracy, Cerigua, Ciudad de Guatemala, 1996, páginas 9-10. 
18. Blancanieva Bendfeltd, Directora de Medios, APCU Thompson Asociados, entrevistada por Rick Rockwell, el mes de julio de 1998, en la Ciudad de Guatemala.

19. Cfr. Principales Medios de Comunicación (Honduras, El Salvador y Guatemala), en Inforpress CentroAmericana, abril de 1998, página 4.

20. Cfr. Alamilla et al., Op. cit., página 10.

21. Entrevista con Bendfeltd.

22. Alamilla et al., $O_{p}$. cit., página 2.

23. Entrevista con Bendfeltd.

24. Ibid.

25. Francisco Medina y Óscar Amílcar Hernández, jefe editorial y de información de $E$ l Periódico, respectivamente, entrevistados por Rick Rockwell, el 16 de marzo de 1998, en San Pedro Sula, Honduras.

26. Edgardo Benítez, editor de El Nuevo Día, entrevistado por Rick Rockwell, el 21 de marzo en 1998, en San Pedro Sula, Honduras.

27. Alberto Fernández, del Departamento de Información del Gobierno de Estados Unidos, entrevistado por Rick Rockwell, el mes de julio de 1998, en Ciudad de Guatemala, Guatemala.

28. Principales Medios de Comunicación (Honduras, El Salvador y Guatemala), página 5.

29. Cfr. Virtue, $O_{p}$. cit., página 215.

30. Alice Chasan, ed., Attacks on the Press in 1997. Comité para Proteger a los Periodistas, Nueva York, 1998, página 195.

31. Encuesta de preferencias hacia los medios, Universidad Centroamericana, Managua, junio de 1998.

32. Nicolás González Revilla, Vicepresidente Ejecutivo de MEDCOM Holdings, entrevistado por Rick Rockwell, el mes de agosto de 1998, en Ciudad de Panamá, Panamá.

33. Diana Martans, Directora de Pauta, entrevistada por Rick Rockwell, durante el mes de agosto de 1998, en Ciudad de Panamá. Panamá.

34. Entrevista con González. Revilla.

35. Gustavo Gorriti. Editor Asociado de La Prensa, entrevistado por Rick Rockwell, el mes de agesto de 1998, en Ciudad de Panamá, Panamá.

36. Entrevista con González Revilla.

37. Juan Luis Correa, Gerente General de La Prensa, entrevistado por Rick Rockwell, agosto, 1998. Ciudad de Panamá, Panamá.

38. Entrevista con Gorriti.

39. Marco Antonio Rivera, productor del Canal 12, entrevistado por Noreen Janus, el mes de mayo de 1998. en San Salvador, El Salvador.

4). Cir. Principales medios de comunicación (Honduras, LI Salvador y Guatemala), página 8.

41. Entrevista con Rivera.

42. Ihid.

43. Principales medios de comunicación (Honduras, Li Salvador y: Guatemala), página 8.

44. Raúl Gallegos. Periodismo Feudal, en Ll Diario de Hoy, 7 de mayo de 1998 página 112.

4.5. Entrevista con Gorriti.

46. James Aparicio, Director de La Estrella de Panamá, entrevistado por Rick Rockwell, el mes de agosto de 1998. Ciudad de Panamá, Panamá.

47. Entrevista con Correa. 
48. Entrevista con Aparicio.

49. Cfr. Virtuc, Op. cit., página 205.

50. Print Media in San Salvador. Departamento de Información estadounidense. abril, 1998.

51. Cfr. Virtue, $O_{\text {p) }}$ cit., p. 205.

52. Cfr. Print Media in San Salvador.

53. Enrique Altamirano, director de El Diario de Hoy, entrevistado por Noreen Janus, el mes de mayo de 1998, en San Salvador, El Salvador.

54. Cristiana Chamorro, antigua editora de La Prensa, entrevistada por Noreen Janus, mayo de 1998, Managua, Nicaragua.

55. Chasan, páginas 195-196. El Comité para Proteger los Periodistas, menciona por lo menos a tres periodistas que murieron como represalia por sus reportajes en 1997.

56. Ibid, páginas 202-203. El Comité señala que el gobicrno panameño intentó expulsar al editor asociado de La Prensa, Gustavo Gorriti, por escribir una serie de reportajes que vinculaban la campaña del Presidente Pérez Balladares a narcotraficantes. 